\title{
Cas3 is a limiting factor for CRISPR-Cas immunity in Escherichia coli cells lacking H-NS
}

\author{
Kristina Majsec ${ }^{1}$, Edward L. Bolt² and Ivana Ivančić-Baće $e^{\text {** }}$
}

\begin{abstract}
Background: CRISPR-Cas systems provide adaptive immunity to mobile genetic elements in prokaryotes. In many bacteria, including E. coli, a specialized ribonucleoprotein complex called Cascade enacts immunity by" an interference reaction" between CRISPR encoded RNA (crRNA) and invader DNA sequences called "protospacers". Cascade recognizes invader DNA via short "protospacer adjacent motif" (PAM) sequences and crRNA-DNA complementarity. This triggers degradation of invader DNA by Cas3 protein and in some circumstances stimulates capture of new invader DNA protospacers for incorporation into CRISPR as "spacers" by Cas1 and Cas2 proteins, thus enhancing immunity. Co-expression of Cascade, Cas 3 and crRNA is effective at giving E. coli cells resistance to phage lysis, if a transcriptional repressor of Cascade and CRISPR, H-NS, is inactivated ( $\Delta$ hns). We present further genetic analyses of the regulation of CRISPR-Cas mediated phage resistance in $\Delta h n s$. coli cells.

Results: We observed that E. coli Type I-E CRISPR-Cas mediated resistance to phage $\lambda$ was strongly temperature dependent, when repeating previously published experimental procedures. Further genetic analyses highlighted the importance of culture conditions for controlling the extent of CRISPR immunity in E. coli. These data identified that expression levels of cas3 is an important limiting factor for successful resistance to phage. Significantly, we describe the new identification that cas3 is also under transcriptional control by H-NS but that this is exerted only in stationary phase cells.
\end{abstract}

Conclusions: Regulation of cas3 is responsive to phase of growth, and to growth temperature in E. coli, impacting on the efficacy of CRISPR-Cas immunity in these experimental systems.

Keywords: CRISPR-Cas, H-NS, PAM, HtpG, Temperature, E. coli

\section{Background}

Escherichia coli K-12 utilises Type I-E CRISPR (Clustered Regularly Interspaced Short Palindromic Repeats) loci to gain immunity to invasive DNA such as bacteriophage ("phage"), dependent on activities of Cas (CRISPR-associated) proteins reviewed in [1-5]. CRISPR loci are composed of the AT-rich leader region followed by arrays of sequence repeats separated by spacers that are homologous to sequences of invading DNA ("protospacers"). CRISPR arrays are transcribed into "pre-crRNA" that is further processed into "crRNA" that contains a full or partial spacer sequence reviewed in [1-5]. In E. coli, crRNA

\footnotetext{
* Correspondence: ivana.ivancic.bace@biol.pmf.hr

${ }^{1}$ Division of Molecular Biology, Faculty of Science, University of Zagreb,

Horvatovac 102a, 10000 Zagreb, Croatia

Full list of author information is available at the end of the article
}

assembled into "Cascade" (CRISPR-associated complex for antiviral defence) is targeted to protospacers in "interference" reactions. E. coli Cascade comprises five proteins: Cse1 (CasA), Cse2 (CasB), Cas7 (CasC), Cas5 (CasD) and Cas6e (CasE) [6-10]. Interference generates base pairing between crRNA and protospacer DNA in an R-loop, displacing the DNA strand that is not complementary to crRNA [6,11-15]. This single stranded DNA is degraded by Cas3 helicase-nuclease [16-19].

Cascade catalyses interference R-loops by a sequential process reliant on recognition of protospacer adjacent motif (PAM) sequences located immediately next to a protospacer on the target protospacer DNA [20-23]. CRISPR arrays lack a PAM sequence, helping to prevent targeting of self-DNA by Cascade [24-26]. In E. coli K-12 PAM 5' ${ }^{\prime}$ CTT-3' is most prevalent ( $\left.80 \%\right)[22,26,27]$, and 
of 64 possible PAMs, five PAMs are tolerated by Cascade to promote interference [11, 22, 25]. The Cse1 (CasA) subunit of Cascade is important for PAM recognition, and for positioning Cas3 to degrade invader DNA [13, 16, 19]. After PAM recognition, stable R-loop formation requires complementarity between the crRNA-DNA in a "seed" region (8-10 nucleotides from the $5^{\prime}$ end of the crRNA spacer sequence). Upon reaching the end of the protospacer the R-loop becomes locked [28] and by pushing Cse2 dimer it induces repositioning of Cse 1 and Cse 2 proteins, and conformational change of the whole Cascade complex [29]. After locking of the R-loop, additional PAM verification guides Cas3 binding near the PAM [13, 19, 29] and degradation of the DNA [11, 15, 29].

"Escape" mutations in phage DNA can reduce the stability of E. coli Cascade R-loops when they arise in a protospacer seed or a PAM, and correspond to reduced resistance to plaque formation [11, 21-23, 25, 30, 31]. Other mutations in phage DNA protospacers are tolerated for interference (e.g. positions 6, 12, 18, 24, 30) [22]. This is because five Cas7 proteins fold over every sixth nucleotide of the crRNA which are flipped outward and do not participate in DNA recognition [8-10]. Recent results showed that the crRNA spacer sequence also has significant role in helping interference machinery to recognize protospacer with single point mutations within the seed sequence or PAM [32]. Escape mutations that block interference promote rapid acquisition of new spacers from the same target DNA, a process called 'primed' adaptation that suggests cross-talk between Cas1-Cas2 DNA capture and alternative binding mode of Cascade that promotes priming [22, 27, 31]. Primed adaptation is a very robust process that tolerates up to 13 mutations either in PAM or protospacer region [22]. Spacers newly acquired during primed adaptation therefore provide elevated protection against invader whose escape mutations were evading robust interference by Cascade [27, 32].

In E. coli $\mathrm{H}-\mathrm{NS}$ (nucleoid-structuring protein) represses transcription of CRISPR and the genes encoding Cascade, Cas1 and Cas2. E. coli LeuO de-represses transcription of genes encoding Cascade, by blocking cooperative spreading of H-NS along the promoter of the initially transcribed Cascade gene, cse1 [33, 34]. In addition to H-NS and LeuO, CRP (cAMP receptor protein) is a transcriptional repressor of cas genes in E. coli $[35,36]$. The CRP binding site in this case overlaps with the LeuO binding site, leading to the proposal that CRP and LeuO compete for binding to the cse1 promoter depending on the cellular availability of cAMP [35]. In contrast to the apparent complexity of transcriptional regulation of Cascade and CRISPR, factors that control transcription of $E$. coli cas 3 have not been identified.
Experimental analyses of CRISPR-Cas in E. coli can overcome influences of $\mathrm{H}-\mathrm{NS}$, LeuO and CRP repression by engineering inducible expression of CRISPR, Cascade and Cas3 from plasmids or their chromosomal loci [27, 37]. Deletion of H-NS ( $\Delta h n s)$, or ectopic over-expression of LeuO in cells with engineered anti- $\lambda$ spacer $(\lambda T 3)$ into CRISPR, promote CRISPR interference observed as enhanced resistance to phage $\lambda$ vir $[34,38]$. In these studies the protospacer targeted by spacer $\lambda \mathrm{T} 3$ crRNA had a nonconsensus PAM 5'-CCA-3' and although resistance to phage $\lambda$ vir from these strains was effective at $30^{\circ} \mathrm{C}$, we noticed that at $37^{\circ} \mathrm{C}$ cells became sensitive to plaque formation. We investigated this further in $\Delta h n s$ cells that had acquired a new spacer $(\lambda c)$ targeting protospacer with the consensus PAM 5'-CTT-3'. We report that the effect of temperature on CRISPR immunity in these E. coli cells was correlated to expression of Cas3 and its chaperone HtpG (high-temperature protein G). Inducible ectopic expression of Cas3 in the presence, but not absence, of chromosomal $h t p G$ rescued resistance to phage at $37^{\circ} \mathrm{C}$. Further research will be required to uncover how temperature causes this effect on activity of the $E$. coli CRISPR-Cas system.

\section{Results}

Temperature-dependent resistance of $\Delta h n s$ E. coli cells to phage $\lambda$ vir is not caused by PAM sequence variation

Genetic analysis of $E$. coli CRISPR-Cas in previous studies established that $\mathrm{H}$-NS represses transcription of the operon encoding Cascade, Cas1-Cas2 (casABCDE12) and CRISPR locus 2.1 [33-35, 38]. Deleting H-NS $(\Delta h n s)$ from cells de-repressed transcription, and efficient resistance to $\lambda$ vir infection at $30{ }^{\circ} \mathrm{C}$ was reported when CRISPR of $\Delta h n s$ cells was engineered to contain an anti- $\lambda$ phage spacer sequence $(\lambda \mathrm{T} 3)[34,38]$. The importance of the $\lambda \mathrm{T} 3$ spacer was highlighted by sensitivity of $\Delta h n s$ cells to $\lambda v i r$ plaque formation compared to $\Delta h n s+\lambda \mathrm{T} 3$ cells [38]. When repeating these experiments we also observed about 100000 fold elevated resistance of $\Delta h n s+\lambda \mathrm{T} 3$ cells to $\lambda v i r$ infection at $30^{\circ} \mathrm{C}$, compared to $\Delta h n s$ cells without $\lambda \mathrm{T} 3$ spacer (Table 1 ). However at $37{ }^{\circ} \mathrm{C}$, in otherwise identical assays, $\Delta h n s+\lambda \mathrm{T} 3$ cells became sensitive to phage (Table 1). Cells with intact $\mathrm{H}$ NS $\left(h n s^{+}\right)$, with or without $\lambda \mathrm{T} 3$, were sensitive to $\lambda$ vir infection at both temperatures (Table 1). There was no difference in sensitivity at $37{ }^{\circ} \mathrm{C}$ between $\Delta h n s$ cells + or $\lambda \mathrm{T} 3$ spacer. If $\lambda \mathrm{T} 3$ spacer was absent from the CRISPR locus 2.1, $\Delta$ hns cells showed threefold increase in resistance at $30{ }^{\circ} \mathrm{C}$ in comparison to $37^{\circ} \mathrm{C}$ (Table 1 ). Therefore using $30{ }^{\circ} \mathrm{C}$ temperature of incubation in infectivity assays is an important factor for promoting resistance of $\Delta h n s+\lambda \mathrm{T} 3$ cells to phage $\lambda$ vir.

The $\lambda \mathrm{T} 3$ spacer sequence engineered into CRISPR used here and in $[37,38]$ has a nucleotide sequence match with the template strand of $\lambda$ phage gene lysis $R$, 
Table 1 E. coli cells lacking H-NS show temperature-dependent resistance to phage

\begin{tabular}{llll}
\hline strain & genotype & \multicolumn{2}{l}{ Plaque forming units (PFUs) } \\
\cline { 2 - 3 } & & $30^{\circ} \mathrm{C}$ & $37^{\circ} \mathrm{C}$ \\
\hline BW25113 & hns $^{+}$ & $3.80 \times 10^{10} \pm 7 \times 10^{9}$ & $4.56 \times 10^{10} \pm 9 \times 10^{9}$ \\
BW39121 & $\Delta h n s$ & $1.20 \times 10^{10} \pm 1.8 \times 10^{9}$ & $4.23 \times 10^{10} \pm 6.6 \times 10^{10}$ \\
BW39651 & $h n s^{+}+\lambda T 3$ & $3.66 \times 10^{10} \pm 7.57 \times 10^{9}$ & $4.03 \times 10^{10} \pm 1.2 \times 10^{10}$ \\
BW39671 & $\Delta h n s+\lambda T 3$ & $\sim 4 \times 10^{5}$ & $4.16 \times 10^{10} \pm 5.5 \times 10^{9}$ \\
\hline
\end{tabular}

$\lambda$ vir

Cell lawns were infected with phage dilutions (from $10^{-2}$ to $10^{-8}$ ) and incubated at either $30^{\circ} \mathrm{C}$ or $37^{\circ} \mathrm{C}$. Cells lacking H-NS ( $\left(\mathrm{hns}\right.$ ) or containing H-NS (hns ${ }^{+}$) had fully operational CRISPR-Cas systems that were engineered with an anti- $\lambda$ spacer $(\lambda T 3)$ as indicated. The average of at least three independent experiments are shown

but the PAM sequence $\left(5^{\prime}-\mathrm{CCA}-3^{\prime}\right.$, Additional file 1 : Figure S1A) deviates from consensus 5'-CTT-3' E. coli PAM [20]. Single nucleotide variations in PAMs may disrupt interference in Type I-E, I-F and Type II CRISPR systems by preventing R-loop priming and degradation of invading DNA [21, 22, 25, 29, 30, 39, 40]. Five PAMs, CAT, CTT, CCT, CTC and CTA found previously $[11,22,25]$, are utilized by Cascade for robust interference, and ten non-consensus PAMs give a partial resistance phenotype [25]. Therefore, PAM 5 '-CCA-3' belongs to the latter group, giving partial resistance to $\lambda v i r$ as expected from previous data [25]. However, recent findings showed that spacer sequence dictates whether mutant PAM sequences will be tolerated for interference or not [32]. We investigated if the observed major difference in phage resistance of $\Delta h n s$ cells at $30^{\circ} \mathrm{C}$ and $37^{\circ} \mathrm{C}$ was related to PAM sequence by introducing spacer targeting protospacer with the consensus PAM $5^{\prime}-\mathrm{CTT}-3^{\prime}$ into CRISPR. To do this we provoked $\Delta h n s+\lambda \mathrm{T} 3 E$. coli to acquire a new spacer. One such $E$. coli derivative containing spacer $(\lambda c)$ targeting phage $\lambda$ vir gene $c I I$ with a $5^{\prime}$-CTT-3' PAM was selected. The procedure is detailed in the methods and supplementary material. The constructed strain (IIB1039; Table 2) also contains $\Delta$ cas1 mutation as a useful controlling factor to uncouple interference from adaptation, enabling focus on interference reaction only. In phage infectivity assays, $h n s^{+} \Delta c a s 1+\lambda c+\lambda \mathrm{T} 3$ cells were sensitive to $\lambda$ vir phage at $30{ }^{\circ} \mathrm{C}$ and $37{ }^{\circ} \mathrm{C}$, as expected because H-NS represses cas genes (Table 3). $\Delta$ hns $\Delta$ cas $1+\lambda c+\lambda \mathrm{T} 3$ cells showed $\sim 10^{8}$ fold increase in resistance at $30{ }^{\circ} \mathrm{C}$ compared to $h n s^{+} \Delta$ cas $1+\lambda c+\lambda \mathrm{T} 3$, and $\sim 10^{3}$ compared to $\Delta h n s \quad \Delta$ cas $1+\lambda \mathrm{T} 3$ cells, but remained sensitive to $\lambda$ vir infection at $37{ }^{\circ} \mathrm{C}$ (Table 3). This showed that $\Delta$ cas 1 mutation did not affect interference as expected and confirmed the importance of a consensus PAM for phage resistance in infectivity assays at $30{ }^{\circ} \mathrm{C}$, explained in previous studies by the effect of variable PAMs on efficacy of interference reactions $[25,29]$. However, added spacer targeting the consensus PAM 5'CTT-3' was not able to repeal the temperature dependent resistance of $\Delta h n s$ cells to $\lambda v i r$ in these assays, which we concluded must be caused by other factor (s).
Transcription and stability of cas3 in $\Delta h n s$ cells is limiting for resistance to phage

We tested if the effect of temperature on phage resistance was influenced by variations in expression of $E$. coli CRISPR-Cas. Robust resistance of $\Delta h n s \Delta$ cas $1+\lambda c+\lambda T 3$ cells to $\lambda$ vir (Table 3 ) suggested all components of CRISPR-Cas were expressed in sufficient amounts at $30{ }^{\circ} \mathrm{C}$. A previous analysis identified increased transcription of genes encoding Cascade and crRNA in $\Delta h n s$ cells grown to mid-log phase, but no such increase in cas 3 transcripts [34]. We explored if levels of Cas3 RNA or protein in cells might correlate to phage resistance under different temperature conditions of infectivity assays.

By using quantitative PCR (qPCR) we compared cas3 transcript levels between $h n s^{+}$and $\Delta h n s$ cells in both mid-log and stationary phases of growth. Relative abundance of cas 3 transcripts was around eight-fold higher in $\Delta h n s$ cells compared to $h n s^{+}$cells when grown to stationary phase, regardless of the temperature being $30{ }^{\circ} \mathrm{C}$ or $37^{\circ} \mathrm{C}(8.99 \pm 3.83$ and $7.59 \pm 1.59)$, but remained similar at mid-log phase $\left(0.9 \pm 0.56\right.$ and $2.44 \pm 1.21$ for $30{ }^{\circ} \mathrm{C}$ and $37{ }^{\circ} \mathrm{C}$, respectively). This suggested that the growth phase was important for the observed difference in the level of cas3 transcripts, not the temperature of incubation. As shown in Fig. 1, only $\Delta h n s+\lambda \mathrm{T} 3$ cells showed significant difference in cas 3 transcripts depending on the temperature of incubation (marked with different letters $\mathrm{d}$ and bc which indicate significant difference in expression values between these two samples $(p<0.05))$. Increased cas 3 transcription at stationary phase at $30^{\circ} \mathrm{C}$ or $37{ }^{\circ} \mathrm{C}$ was not observed if $\mathrm{H}-\mathrm{NS}$ was present, and presence of $\lambda c+\lambda \mathrm{T} 3$ spacers had no effect on cas 3 transcript levels (Fig. 1). These results suggest that the sensitivity of $\Delta h n s$ cells to $\lambda v i r$ plaques at $37{ }^{\circ} \mathrm{C}$ is unlikely to be due to lack of cas3 transcription. We therefore tested if Cas3 protein levels may influence phage sensitivity at $37{ }^{\circ} \mathrm{C}$. The chaperone HtpG was also considered here, because HtpG increases steady-state Cas3 protein levels in $E$. coli, which correlated to stimulation of interference reactions, carried out at $32{ }^{\circ} \mathrm{C}$ [41]. We reasoned that sensitivity of $\Delta$ hns $\Delta$ cas $1+\lambda c+\lambda \mathrm{T} 3$ cells to $\lambda v i r$ at $37{ }^{\circ} \mathrm{C}$ caused by reduced or unstable Cas 3 protein might be 
Table $\mathbf{2}$ List of strains used in this study

\begin{tabular}{|c|c|c|}
\hline Bacterial strain & Relevant genotype & Source or reference \\
\hline EB304 & MG1655, $\Delta$ cas3::apra & [44] \\
\hline BSN22 & W3110, $\Delta$ hns:: cat & [46] \\
\hline \multirow[t]{2}{*}{ BW25113 } & $\mathrm{F}^{-} \mathrm{rrnB} \Delta$ lacZ4748 (:.rrnB-3) hsdR514 $\Delta$ (araBAD) $567 \Delta\left(\right.$ rhaBAD) $568 \mathrm{rph}-1 \lambda^{-}$ & [47] \\
\hline & Bacterial strains related to BW25113 & \\
\hline BW39121 & $+\Delta h n s:: k a n$ & [38] \\
\hline JW0462 & $+\Delta h t p G: . k a n$ & [41] \\
\hline BW40114 & $+\mathrm{F}^{\prime}\left(\right.$ proAB ${ }^{+}$lac $\left.1^{9} Z \Delta \mathrm{M} 15:: \operatorname{Tn} 10\right)$ lacUV5-cas3 cat::araBp8-casA & [27] \\
\hline BW39651 & $+\lambda T 3$ spacer & [38] \\
\hline BW39671 & $+\lambda T 3 \Delta h n s:: k a n$ & [38] \\
\hline BW39183 & $+\Delta \operatorname{cas} 7:: k a n$ & [38] \\
\hline IIB848 & $+\lambda T 3 \Delta$ cas3::apra & recombineering using pKD46 \\
\hline IIB870 & $+\lambda T 3 \Delta$ cas3::apra & P1. IIB848 × BW39651 \\
\hline IIB965 & $+\lambda T 3 \Delta \operatorname{cas} 1:: k a n$ & P1. BW39183 × BW39651 \\
\hline IIB966 & $+\lambda T 3 \Delta \operatorname{cas} 1:: k a n \Delta h n s:$. cat & P1. BSN22 $\times \| B 965$ \\
\hline IIB969 & $+\lambda T 3$ lacUV5-cas3 cat::araBp8-casA & P1. BW40114×BW39651 \\
\hline IIB969e & $+\lambda c+\lambda T 3$ lac UV5-cas3 cat:araBp8-casA & Selection of $\lambda^{r}$ colony with phage acquired spacer \\
\hline IIB1039 & $+\lambda c+\lambda T 3 \Delta \operatorname{cas} 7:: k a n$ & P1. BW39183 $\times \|$ IIB969e (selection $\mathrm{Km}^{r} \mathrm{Ch}^{\mathrm{s}}$ and PCR of the CRISPR-1 region) \\
\hline IIB1040 & $+\lambda c+\lambda T 3 \Delta$ cas 1::kan $\Delta$ hns:: cat & P1. BSN22 × IB1039 \\
\hline IIB1043 & $+\lambda c+\lambda T 3 \Delta \operatorname{cas} 1:: k^{s} n^{s}$ & Removal of kan cassette by pCP20 plasmid \\
\hline IIB1063 & $+\lambda c+\lambda T 3$ lacUV5-cas3 cat:araBp8-casA $\Delta h t p G:: k a n$ & \\
\hline IIB1065 & $+\lambda c+\lambda T 3 \Delta \operatorname{cas} 1:: k_{a n}^{s} \Delta h t p G:: k a n$ & P1. JW0462 × IB1043 \\
\hline IIB1066 & $+\lambda c+\lambda T 3 \Delta$ cas 1::kan $\Delta$ htpG::kan $\Delta$ hns.:"cat & P1. BSN22 × IIB1065 \\
\hline
\end{tabular}


Table 3 Temperature-dependent resistance of $\Delta h n s$ cells to phage $\lambda$ vir in the presence of phage acquired spacer

\begin{tabular}{llll}
\hline strain & genotype & Plaque forming units (PFUs) & \\
\cline { 2 - 4 } & & $30^{\circ} \mathrm{C}$ & $37^{\circ} \mathrm{C}$ \\
\hline IIB965 & $h n s^{+} \Delta$ cas1 $+\lambda T 3$ & $4.63 \times 10^{10} \pm 1.6 \times 10^{10}$ & $5.8 \times 10^{10} \pm 1.14 \times 10^{10}$ \\
IIB966 & $\Delta$ hns $\Delta$ cas1 $+\lambda T 3$ & $\sim 5 \times 10^{5}$ & $3.35 \times 10^{10} \pm 9 \times 10^{9}$ \\
IIB1039 & $h n s^{+} \Delta \operatorname{cas} 1+\lambda c+\lambda T 3$ & $3.37 \times 10^{10} \pm 2.5 \times 10^{9}$ & $2.97 \times 10^{10} \pm 9.7 \times 10^{9}$ \\
IIB1040 & $\Delta h n s \Delta \operatorname{cas} 1+\lambda c+\lambda T 3$ & $\sim 3 \times 10^{2}$ & $2 \times 10^{10} \pm 6 \times 10^{9}$ \\
\hline
\end{tabular}

Cell lawns of strains $h_{n s}{ }^{+}(\Delta \operatorname{cas} 1)+\lambda c+\lambda T 3$ and $\Delta h n s(\Delta \operatorname{cas} 1)+\lambda c+\lambda T 3$ were infected with phage dilutions (from $10^{\circ}$ to $10^{-8}$ ) and incubated at either $30^{\circ} \mathrm{C}$ or $37^{\circ} \mathrm{C}$. The average of at least three independent experiments are shown

overcome by plasmid expression of HtpG or Cas3. However, we observed that (Fig. 2a) expression of only Cas3 from plasmid restored resistance of $\Delta h n s \Delta c a s 1+\lambda c+\lambda \mathrm{T} 3$ cells to $\lambda$ vir at $37{ }^{\circ} \mathrm{C}$ comparably to at $30{ }^{\circ} \mathrm{C}$, while cells containing empty plasmid vectors (pBAD or pUC19) or HtpG expressing plasmid remained sensitive. These results suggest that endogenous levels of functionally active Cas3 in $\Delta h n s \Delta c a s 1+\lambda c+\lambda \mathrm{T} 3$ cells are too low to be relieved by elevated levels of HtpG at $37^{\circ} \mathrm{C}$. Given the importance of HtpG for phage resistance it was expected that elimination of HtpG from $\Delta h n s \Delta c a s 1+\lambda c+\lambda \mathrm{T} 3$ cells $(\Delta h t p G \Delta h n s$ $\Delta$ cas $1+\lambda c+\lambda \mathrm{T} 3$ ) would cause sensitivity to phage at both $30{ }^{\circ} \mathrm{C}$ and $37{ }^{\circ} \mathrm{C}$ (Fig. 2b), compared to phage resistance observed in Fig. 2a. Indeed, plaques were observed at $30^{\circ} \mathrm{C}$ in $\Delta h t p G \Delta h n s \Delta c a s 1+\lambda c+\lambda \mathrm{T} 3$ cells with or without empty plasmid controls. However, individual plaques were not visible, so the number of PFU is estimation (Fig. 2b). Plasmid expression of Cas3 (pCas3) in

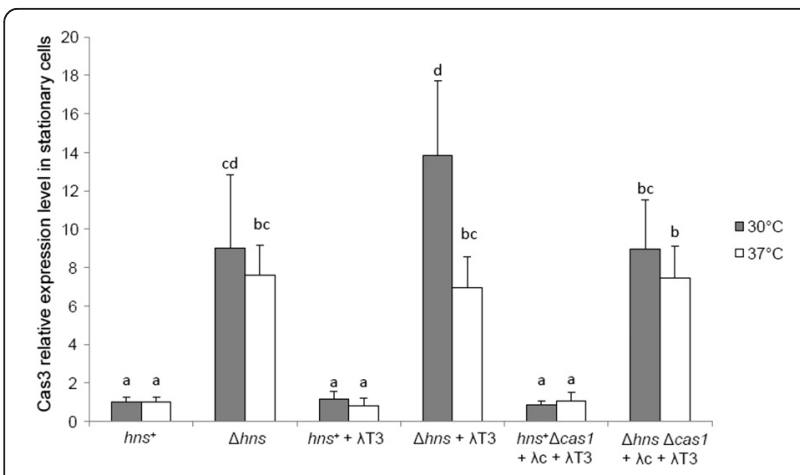

Fig. 1 Cas3 is transcribed in cells lacking $\mathrm{H}-\mathrm{NS}$ at both temperatures of incubation in stationary phase of growth. QPCR analysis extended to $\Delta$ hns $\Delta$ casl and hns $^{+} \Delta$ cas 1 cells containing $\lambda$ T3 and/or $\lambda c$ anti-lambda spacer. Relative expression levels of cas 3 transcripts are measured in cells grown to stationary phase at indicated temperatures of incubation with groES as reference gene. Error bars represent normalized error of respective duplicates. Histogram bars marked with different letters (a for $\mathrm{hns}^{+}$samples, and b, bc, cd and d for $\Delta$ hns samples) indicate significant difference between expression values, while samples that share a letter in the notation (e.g. b, bc, cd or $d$ and cd) do not have statistically different expression values. Cas3 expression levels were compared across all samples, and two expression values were considered significantly different as evaluated by One-way ANOVA Duncan Multiple Range post-hoc test $(p<0.05)$
$\Delta h t p G \Delta h n s \Delta c a s 1+\lambda c+\lambda \mathrm{T} 3$ cells was sufficient for phage resistance at $30{ }^{\circ} \mathrm{C}$ (Fig. 2b) indicating that elevated amounts of Cas3 is efficient in phage defence independently of HtpG at $30{ }^{\circ} \mathrm{C}$ as shown before [41]. In contrast, elevated levels of Cas3 (pCas3) in $\Delta h t p G$ $\Delta h n s \Delta c a s 1+\lambda c+\lambda \mathrm{T} 3$ cells did not rescue phage resistance at $37{ }^{\circ} \mathrm{C}$ confirming the importance of HtpG in maintaining functional levels of Cas3 in phage defence. As expected, although plasmid expression of HtpG (pHtpG) in $\Delta h t p G \Delta h n s+\lambda c+\lambda \mathrm{T} 3$ cells rescued phage resistance at $30{ }^{\circ} \mathrm{C}$, it did not at $37{ }^{\circ} \mathrm{C}$ (Fig. 2b). Given the known interplay of HtpG and Cas3 in promoting CRISPR interference in $E$. coli, these results suggest that levels of Cas3 protein are the limiting factor for resistance to $\lambda v i r$ phage infection in $\Delta h n s$ cells at $37^{\circ} \mathrm{C}$. Overall, these results show that endogenous levels of Cas3 are expressed in low but sufficient amounts for the CRISPR-Cas mediated immunity in cells lacking $\mathrm{H}$ NS grown to stationary phase at $30{ }^{\circ} \mathrm{C}$, but that the levels of functionally active Cas 3 becomes limiting at $37{ }^{\circ} \mathrm{C}$ and require increased levels of Cas3.

\section{Discussion}

By manipulating the expression of H-NS and CRISPRCas in $E$. coli cells we identified that stability or activity of Cas3, with HtpG present, is a limiting factor for resistance to phage $\lambda v i r$ at $37{ }^{\circ} \mathrm{C}$. Our genetic analyses of CRISPR interference at $30{ }^{\circ} \mathrm{C}$ agreed with previous studies, by observing robust phage resistance when cells were lacking $\mathrm{H}-\mathrm{NS}$ repressor $(\Delta h n s)$, and when an anti- $\lambda$ spacer could target protospacer DNA next to a consensus PAM, 5'-CTT-3'. However, the same assays at $37^{\circ} \mathrm{C}$ resulted in a dramatic loss of phage resistance that had not been observed previously. Phage resistance could be restored at $37{ }^{\circ} \mathrm{C}$, to levels comparable with resistance at $30{ }^{\circ} \mathrm{C}$, by inducible expression of cas 3 from plasmids.

Previous analyses of cas 3 transcription sampled only during mid-log growth and showed no difference between $\Delta h n s$ cells compared to $h n s^{+}$cells, unlike Cascade genes and crRNA that were much increased in $\Delta h n s$ cells [34]. We measured cas3 transcripts in mid-log and stationary phase, observing that $\Delta h n s$ cells contained eight-fold more cas3 transcript compared to $\mathrm{hns}^{+}$cells at 

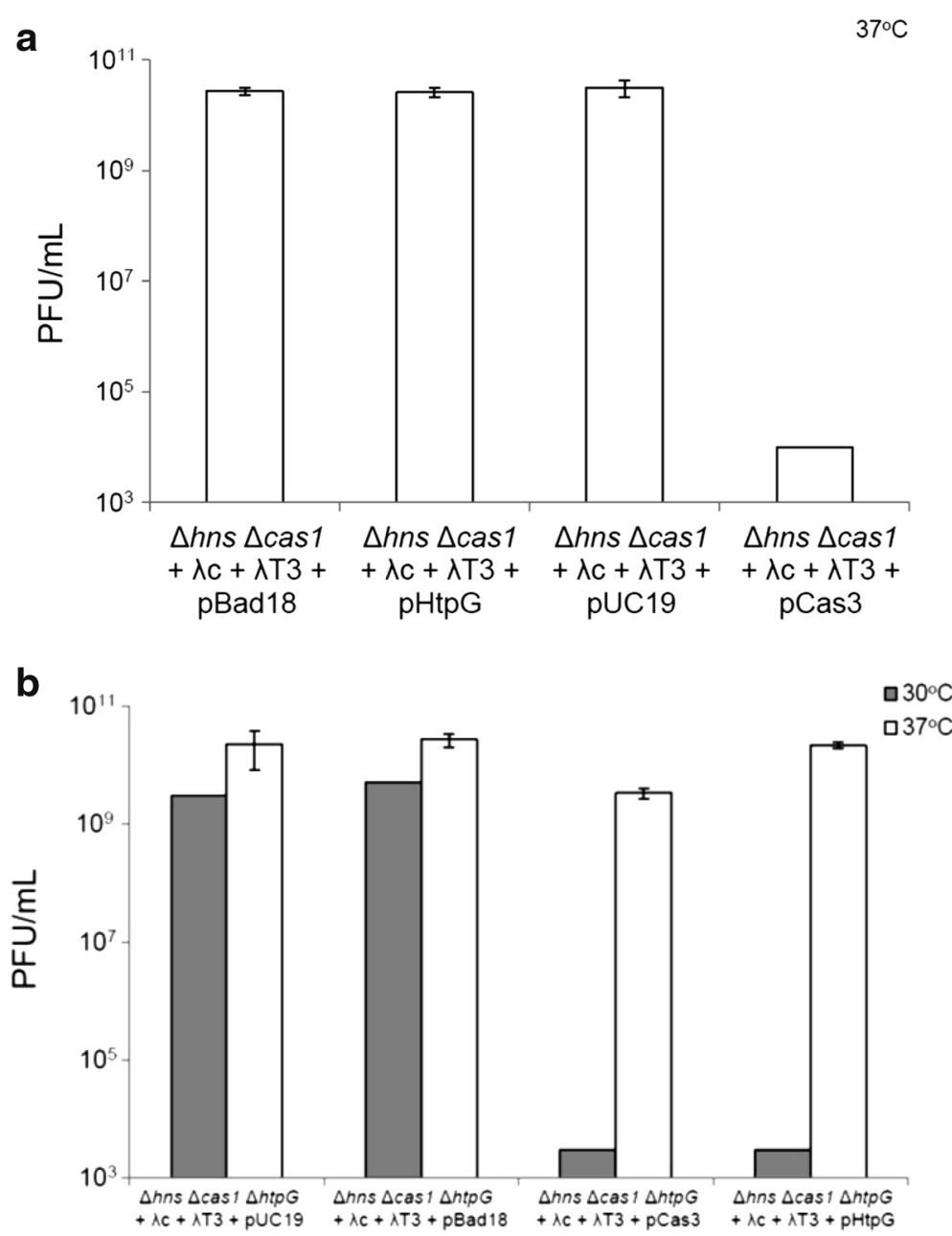

Fig. $2 \mathrm{HtpG}$ is required for resistance to $\lambda$ vir at $30^{\circ} \mathrm{C}$ and $37^{\circ} \mathrm{C}$ to prevent Cas 3 instability. a $E$. coli cell lawns of strain $\Delta h n s \Delta$ cas $1+\lambda c+\lambda T 3$ (IIB1040) transformed with pCas3 and pHtpG expressing plasmids and empty vector controls were infected with phage dilutions (from $10^{\circ}$ to $10^{-8}$ ) and incubated at $37^{\circ} \mathrm{C}$. Bars represent average and SD of the number of plaque forming units (PFUs) per ml from three independent experiments. b E. coli cell lawns of strains $\Delta h n s \Delta$ cas $1+\lambda c+\lambda T 3$ (IIB1040) and $\Delta h t p G \Delta h n s \Delta$ cas $1+\lambda c+\lambda T 3$ (IIB1066) and IIB1066 transformed with pCas3 and pHtpG expressing plasmids, were infected with phage dilutions (from $10^{\circ}$ to $10^{-8}$ ) and incubated at either $30^{\circ} \mathrm{C}$ or $37^{\circ} \mathrm{C}$. Bars represent average and SD of the number of plaque forming units (PFUs) per $\mathrm{ml}$ from three independent experiments

$30{ }^{\circ} \mathrm{C}$ and $37{ }^{\circ} \mathrm{C}$. This is significant because infectivity assays for measuring resistance of $E$. coli to $\lambda$ vir use cells in stationary phase. We conclude from this analysis that H-NS regulates expression of the cas3 gene, as well as Cascade and crRNA, but possibly does so under more specific growth conditions.

Recently it was highlighted that Cas3 requires HtpG chaperone for CRISPR interference assays [41]: Overexpression of HtpG or Cas3 from plasmids in $h t p G$ deficient cells $(\Delta h t p G \Delta h n s)$ rescued transformation-efficiency at $32{ }^{\circ} \mathrm{C}$. We observed similar interplay of HtpG and Cas3 at $30{ }^{\circ} \mathrm{C}$ because plasmid overexpression of either HtpG or Cas3 (pHtpG/pCas3) could restore phage resistance to $\Delta h t p G \Delta h n s \Delta c a s 1+\lambda c+\lambda \mathrm{T} 3$ (IIB1066) cells that were otherwise sensitive to phage infection (Fig. 2b). Interestingly, the pCas3 alone did not restore phage resistance to
$\Delta h t p G \Delta$ hns $\Delta$ cas $1+\lambda c+\lambda \mathrm{T} 3$ cells at $37{ }^{\circ} \mathrm{C}$ (Fig. 2b) but did to $h t p G^{+} \Delta h n s \Delta c a s 1+\lambda c+\lambda \mathrm{T} 3$ (IIB1040) cells at $37^{\circ} \mathrm{C}$ (Fig. 2a), while pHtpG was unable to sustain phage resistance to any $\Delta h n s$ cells at $37{ }^{\circ} \mathrm{C}$. Thus, HtpG is important for CRISPR-system activity in $\Delta h n s$ cells at $37^{\circ} \mathrm{C}$, but its overexpression from plasmid alone cannot overcome limiting amounts of functionally active Cas 3 at $37{ }^{\circ} \mathrm{C}$. Further research will be required to better understand the reasons and mechanisms of Cas3 instability in $\Delta h n s$ cells at $37^{\circ} \mathrm{C}$.

In addition to four $\sigma^{70}$ ("house-keeping" sigma factor)promoters in CRISPR-Cas area, two potential $\sigma^{32}$ (heatshock sigma factor)-dependent promoters have been mapped within coding regions of cas 7 and cas1 [42, 43], suggesting another possible link between CRISPR-Cas immunity and heat-shock response. In summary, expression and activity of the CRISPR-Cas system in E. coli seem to 
be linked to global stress responses, such as H-NS global repressor, heat stress and CRP-cAMP. Perhaps, CRISPRCas immunity is designed to become activated during certain phase of growth, at specific environmental habitats and temperature, and instability of the Cas 3 may be the mechanism for inactivation of the CRISPR-Cas defence either at inappropriate temperature of incubation or when degradation of foreign DNA is completed.

\section{Conclusions}

We observed that the ability of an E. coli CRISPR-Cas system to resist lysis by phage $\lambda$ was strongly influenced by temperature. Genetic analysis of this effect indicated that sensitivity to phage at $37{ }^{\circ} \mathrm{C}$ was caused by limiting amounts of Cas3, rather than effects of PAM sequence variations on Cascade interference reactions. We show that transcription of cas3 is controlled by H-NS: elimination of $\mathrm{H}-\mathrm{NS}$ from cells correlated to eight-fold increased levels of cas 3 transcript, specifically in stationary phase growth. At $37^{\circ} \mathrm{C}$, increased expression of cas 3 is required for resistance to $\lambda$ infection. This suggests that endogenous expression and activity of Cas3 is responsive to signals associated with growth phase and temperature in E. coli.

\section{Methods}

\section{Strains and plasmids}

The E. coli K-12 strains used in this study are described in the Table 2.

Plasmids used were: pEB526 expressing Cas3 [44], and HtpG expressing plasmid was from pBAD18 plasmid [41].

\section{Media and general methods}

LB broth and agar media (10 $\mathrm{g} \mathrm{L}^{-1}$ bacto-tryptone, $5 \mathrm{~g} \mathrm{~L}^{-1}$ yeast extract, $10 \mathrm{~g} \mathrm{~L}^{-1} \mathrm{NaCl}$ ), supplemented with $15 \mathrm{~g}$ of agar for solid media. When required appropriate antibiotics were added to LB plates at final concentrations: ampicillin at $100 \mu \mathrm{g} / \mathrm{ml}$, kanamycin at $40 \mu \mathrm{g} / \mathrm{ml}$, apramycin $30 \mu \mathrm{g} / \mathrm{ml}$ and chloramphenicol at $15 \mu \mathrm{g} / \mathrm{ml}$. Mutant bacterial strains were made by P1vir transduction and selected for the appropriate antibiotic resistance [45]. When important (for generating IIB969 and IIB1039), the genotype (presence of $\lambda \mathrm{T} 3$ and $\lambda \mathrm{c}$ spacers) of many transductants were screened by colony PCR using the same primers (CRISPR I-R: 5' -GAGATGCAGGCCATCGGA3' and spacer 4: 5'-GCGACCGCTCAGAAATTCCA GACCCGATCCAAA-3') as for spacer acquisition and PCR products were sequenced for confirmation.

\section{Phage sensitivity assay by plaque formation}

Cells were grown to saturation overnight in LB medium supplemented with $0.02 \%$ maltose. LB plates were overlaid with $3.5 \mathrm{ml} 0.6 \% \mathrm{LB}$ top agar containing $0.2 \mathrm{ml}$ of cells. After solidification, $10 \mu \mathrm{l}$ aliquots of serially diluted phages in $10 \mathrm{mM} \mathrm{MgSO}_{4}$ were spotted on the surface of the plate and allowed to soak. Plates were incubated overnight at $30^{\circ} \mathrm{C}$ or $37^{\circ} \mathrm{C}$. When required, $1 \mathrm{mM}$ IPTG (isopropyl- $\beta$-D-thiogalactoside) and $0.2 \% \mathrm{~L}$-arabinose were added in plates and top agar. The sensitivity of the cells to infection was represented as the plaque-forming units (PFUs) by counting plaques from several dilutions, and calculating their number per $\mathrm{mL}$.

\section{Spacer acquisition experiments to generate a consensus PAM for interference}

Spacer acquisition was performed according to [27]. Strain IIB969 with cas genes fused to inducible promoters and containing the anti-lambda $\lambda \mathrm{T} 3$ spacer in CRISPR locus 2.1 (Table 2) was grown at $37{ }^{\circ} \mathrm{C}$ at $200 \mathrm{rpm}$ to $\log$ phase in LB medium containing $1 \mathrm{mM}$ IPTG and $0.2 \%$ L-arabinose until $\mathrm{OD}_{600}$ was 0.4-0.5, and mixed with $\lambda$ vir lysate at appropriate $\mathrm{MOI}=1$. Cellphage mixture was incubated for 15 minutes without agitation at $37^{\circ} \mathrm{C}$. The mixture was then diluted 10 fold with fresh LB medium containing the same inducers and incubated at $37{ }^{\circ} \mathrm{C}$ for at least two hours, in most cases overnight. Aliquots were spread on LB plates with IPTG and arabinose and incubated overnight at $37{ }^{\circ} \mathrm{C}$. CRISPR expansion was monitored by PCR using appropriate pairs of primers specific for CRISPR locus 2.1 mentioned above.

Several PCR products of fragments of CRISPR locus 2.1 (Additional file 1: Figure S1B) were sent for sequencing in Macrogene service. One lambda resistant derivative was kept for further research (IIB969e, Table 2). It contained phage-acquired anti- $\lambda$ spacer targeting $\lambda c I I$ gene (called $\lambda c$ ) with consensus PAM 5'-CTT-3' (Additional file 1: Figure S1C). $\Delta h n s+\lambda c+\lambda \mathrm{T} 3$ strain was made by $\mathrm{P} 1$ transduction using donor strain $\Delta$ cas $1:$ : $\mathrm{Km}^{\mathrm{r}}$ (BW39183) and selecting for $h_{n s^{+}}$recombinant strain with two extra spacers in the CRISPR locus 2.1 (strain IIB1039; Table 2) and later introducing $\Delta h n s \mathrm{mu}-$ tation (strain IIB1040; Table 2). The $\Delta$ cas 1 mutation was chosen to create $\Delta h n s+\lambda c+\lambda \mathrm{T} 3$ cells because cas1 gene is not required for interference [37].

\section{RNA extraction and qPCR}

Total RNA was extracted from mid $\log \left(\mathrm{OD}_{600}=0.4-0.5\right)$ and overnight cultures incubated at $30{ }^{\circ} \mathrm{C}$ or $37{ }^{\circ} \mathrm{C}$. $1.5 \mathrm{ml}$ of each culture was used and the cell pellet was resuspended in cold $10 \mathrm{mM}$ EDTA and $50 \mathrm{mM}$ sodium citrate and Trizol LS (Invitrogen) was used to extract total RNA following the instructions from the manufacturer. The same amounts of RNA $(1 \mu \mathrm{g})$ was first treated by DNase I, diluted 10 fold and $2 \mu \mathrm{l}$ of each sample (in duplicate) was used as a template for one step amplification reaction using One Step SYBR Prime Script RTPCR Kit II (Takara Bio. Inc.). The PCR reactions were performed on a 7500 Fast Real Time PCR System (Applied Biosystems) and analysed using 7500 Software 
v.2.0.6. (Applied Biosystems). As an internal control the groES gene was used. Fold change of the cas3 gene transcription was calculated using relative quantification with groES as endogenous control and cas3 gene transcript from E. coli BW25113 (wild type) abundance as calibrator. All PCR reactions were performed in triplicate. Control PCRs without template were performed to monitor general contamination levels. Results of qPCR ( $\triangle \mathrm{Ct}$ values) were analyzed by one-way analysis of variance (ANOVA) using STATISTICA 12.0 (StatSoft Inc, USA) software package. Duncan Multiple Range Test was used for post-hoc analysis. Differences between two sample means were considered statistically significant at $p<0.05$.

Primers used were:

\section{Cas 3-F: 5' -ATCGCGTCAATGTACCCTTC-3' Cas3-R: 5' -TCCAGCCAAAGTAACCCATC-3' groES-F: $5^{\prime}$-CTG GAT CGT CAA GCG TAA AG-3' groES-R: 5' -CAA GGA TAC GGC CAT TGC-3'}

\section{Additional file}

Additional file 1: Figure S1. Properties of PAM in $\lambda T 3$ spacer and phage acquired spacer (A). Sequence complementarity between $\lambda T 3$ spacer and proto-spacer in lambda with the PAM 5' CCA $3^{\prime}$ highlighted in red type. (B) Detection of new spacers acquired in CRISPR locus 2.1. The agarose gel shows products of PCR amplified CRISPR 2.1 from E. coli cells IIB969 (lane C "control"), and two phage resistant derivatives after phage challenge of IIB969 (lanes a and b). The PCR fragment size is 723 bp before and 784 bp after spacer acquisition (C). $\lambda$ c spacer sequence from the strain IIB969e is presented paired with proto-spacer in lambda (targeting gene $\mathrm{cl}$ ) with the PAM 5'-CTT-3' highlighted in red type. (JPG 311 kb)

\section{Abbreviations \\ CAMP: cyclic AMP; Cas: CRISPR-associated; Cascade: CRISPR-associated complex for antiviral defence; CRISPR: clustered regularly interspaced short palindromic repeats; CRP: CAMP receptor protein; CrRNA: CRISPR-RNA; E. coli: Escherichia coli; H-NS: nucleoid-structuring protein; HtpG: high- temperature protein G; MOl: multiplicity of infection; OD: optical density; PAM: protospacer adjacent motif; PFU: plaque forming units; $\lambda$ : lambda.}

\section{Competing interests}

The authors declare that they have no competing interests.

\section{Authors' contributions}

KM and IIB performed the experiments and KM performed statistical analyses. IIB and ELB designed the study and analysed the data. IIB supervised experiments and IIB and ELB wrote the manuscript. All authors read and approved the final version of the manuscript.

\section{Acknowledgements}

This work was supported by Grant 119-1191196-1201 from the Croatian Ministry of Science, Education and Sports, and Grants 202309 and 202761 from the University of Zagreb. We are grateful to Prof. Udi Qimron for providing us plasmid $\mathrm{pHtpG}$ and $h t p G$ mutant. We are also very grateful to Dr. E. Semenova, Prof. K. Severinov, and Prof. B. E. Uhlin for strains and students Danijel Sumpor, Mario Stojanović and Karolina Konevski for practical assistance.

\section{Author details}

'Division of Molecular Biology, Faculty of Science, University of Zagreb, Horvatovac 102a, 10000 Zagreb, Croatia. ${ }^{2}$ School of Life Sciences, University of Nottingham, Medical School, Nottingham NG7 2UH, UK.
Received: 1 June 2015 Accepted: 25 February 2016

Published online: 08 March 2016

\section{References}

1. van der Oost J, Westra ER, Jackson RN, Wiedenheft B. Unravelling the structural and mechanistic basis of CRISPR-Cas systems. Nat Rev Microbiol. 2014;12:479-92.

2. Bhaya D, Davison M, Barrangou R. CRISPR-Cas systems in bacteria and archaea: versatile small RNAs for adaptive defense and regulation. Annu Rev Genet. 2011;45:273-97.

3. Westra ER, Swarts D, Staals R, Jore MM, Brouns SJ, van der Oost J. The CRISPRS, they are a-changin': how prokaryotes generate adaptive immunity. Annu Rev Genet. 2012:46:311-38.

4. Wiedenheft B, Sternberg SH, Doudna JA. RNA-guided genetic silencing system in bacteria and archaea. Nature. 2012;482:175-82.

5. Sorek R, Lawrence CM, Wiedenheft B. CRISPR-mediated adaptive immune systems in bacteria and archaea. Annu Rev Biochem. 2013;82:237-66.

6. Jore MM, Lundgren $M$, Van Duijn E, Bultema JB, Westra ER, et al. Structural basis for CRISPR RNA-guided recognition by Cascade. Nat Struct Mol Biol. 2011;18:529-36.

7. Wiedenheft B, Lander GC, Zhou K, Jore MM, Brouns SJ, van der Oost J, et al. Structures of the RNA-guided surveillance complex from a bacterial immune system. Nature. 2011;477:486-9.

8. Zhao H, Sheng G, Wang J, Wang M, Bunkoczi G, et al. Crystal structure of the RNA-guided immune surveillance Cascade complex in Escherichia coli. Nature. 2014:515:147-50

9. Jackson RN, Golden SM, Van Erp PB, Carter J, Westra ER, et al. Crystal structure of the CRISPR RNA-guided surveillance complex from Escherichia coli. Science. 2014;345:1473-9.

10. Mulepati S, Héroux A, Bailey S. Structural biology. Crystal structure of a CRISPR RNA-guided surveillance complex bound to a ssDNA target. Science. 2014;345:1779-84.

11. Westra ER, Van Erp PB, Künne T, Wong SP, Staals RH, et al. CRISPR immunity relies on the consecutive binding and degradation of negatively supercoiled invader DNA by Cascade and Cas3. Mol Cell. 2012;46:595-605.

12. Ivančić-Baće I, Howard JA, Bolt EL. Tuning in to interference: R-loops and cascade complexes in CRISPR immunity. J Mol Biol. 2012:422:607-16.

13. Hochstrasser ML, Taylor DW, Bhat P, Guegler CK, Sternberg SH, et al. CasA mediates Cas3-catalyzed target degradation during CRISPR RNA-guided interference. Proc Natl Acad Sci U S A. 2014;111:6618-23.

14. Mulepati S, Bailey S. In vitro reconstitution of an Escherichia coli RNA-guided immune system reveals unidirectional, ATP-dependent degradation of DNA target. J Biol Chem. 2013;288:22184-92.

15. Sinkunas T, Gasiunas G, Waghmare SP, Dickman MJ, Barrangou R, et al. In vitro reconstitution of Cascade-mediated CRISPR immunity in Streptococcus thermophilus. EMBO J. 2013;32:385-94

16. Gong B, Shin $\mathrm{M}$, Sun J, Jung $\mathrm{C}-\mathrm{H}$, Bolt EB, et al. Molecular insights into DNA interference by CRISPR-associated nuclease-helicase Cas3. Proc Natl Acad Sci U S A. 2014;111:16359-64.

17. Beloglazova N, Petit P, Flick R, Brown G, Savchenko A, Yakunin AF. Structure and activity of Cas3 HD nuclease MJ0384, an effector enzyme of the CRISPR interference. EMBO J. 2011;30:4616-27.

18. Sinkunas T, Gasiunas G, Fremaux C, Barrangou R, Horvath P, Siksnys V. Cas3 is a single-stranded DNA nuclease and ATP-dependent helicase in the CRISPR-Cas immune system. EMBO J. 2011;30:1335-42.

19. Huo Y, Nam KH, Ding F, Lee H, Wu L, et al. Structures of CRISPR Cas3 offer mechanistic insights into Cascade-activated DNA unwinding and degradation. Nat Struct Mol Biol. 2014;21:771-7.

20. Mojica FJ, Díez-Villaseňor C, García-Martínez J, Almendros J. Short motif sequences determine the targets of the prokaryotic CRISPR defence system. Microbiology. 2009;155:733-40.

21. Semenova E, Jore MM, Datsenko KA, Semenova A, Westra ER, et al. Interference by clustered regularly interspaced short palindromic repeat (CRISPR) RNA is governed by a seed sequence. Proc Natl Acad Sci U S A. 2011;108:10098-103.

22. Fineran PC, Gerritzen MJ, Suárez-Diez M, Künne T, Boekhorst J, et al. Degenerate target sites mediate rapid primed CRISPR adaptation. Proc Natl Acad Sci U S A. 2014:111:E1629-38.

23. Blosser TR, Loeff L, Westra ER, Vlot M, Künne T, et al. Two distinct DNA binding modes guide dual roles of a CRISPR-Cas protein complex. Mol Cell. 2015;58:60-70. 
24. Sashital DG, Wiedenheft B, Doudna JA. Mechanism of foreign DNA selection in a bacterial adaptive immune system. Mol Cell. 2012;48:606-15.

25. Westra ER, Semenova E, Datsenko KA, Jackson RN, Wiedenheft B, Severinov $K$, et al. Type I-E CRISPR-Cas systems discriminate target from non-target DNA through base pairing-independent PAM recognition. Plos Genet. 2013;9, e1003742.

26. Swarts DC, Mosterd C, Van Passel MW, Brouns SJ. CRISPR interference directs strand specific spacer acquisition. Plos ONE. 2012;7, e35888.

27. Datsenko KA, Pougach K, Tikhonov A, Wanner BL, Severinov K, Semenova E. Molecular memory of prior infections activates the CRISPR-Cas adaptive bacterial immunity system. Nat Commun. 2012;3:945.

28. Szczelkun MD, Tikhomirova MS, Sinkunas T, Gasiunas G, Karvelis T, et al. Direct observation of R-loop formation by single RNA-guided Cas9 and Cascade effector complexes. Proc Natl Acad Sci U S A. 2014;111:9798-803.

29. Rutkauskas M, Sinkunas T, Songailiene I, Tikhomirova MS, Siksnys V, Seidel R. Directional R-loop formation by the CRISPR-Cas surveillance complex Cascade provides efficient off-target site rejection. Cell Reports. 2015;10:1534-43.

30. Deveau H, Barrangou R, Garneau JE, Labonté J, Fremaux C, et al. Phage response to CRISPR-encoded resistance in Streptococcus thermophilus. J Bacteriol. 2008;190:1390-400.

31. Redding S, Sternberg SH, Marshall M, Gibb B, Bhat P, et al. Surveillance and processing of foreign DNA by the Escherichia coli CRISPR-Cas system. Cell. 2015;163:854-65.

32. Xue C, Seetharam AS, Musharova O, Severinov K, Brouns SJJ, et al. CRISPR interference and priming varies with individual spacer sequences. Nucleic Acids Res. 2015:43:10831-47.

33. Pul Ü, Wurm R, Arslan Z, Geissen R, Hofmann N, Wagner R. Identification and characterization of E. coli CRISPR-Cas promoters and their silencing by H-NS. Mol Microbiol. 2010;75:1495-512.

34. Westra ER, Pul Ü, Heidrich N, Jore MM, Lundgren M, et al. H-NS-mediated repression of CRISPR-based immunity in Escherichia coli K12 can be relieved by transcription activator LeuO. Mol Microbiol. 2010;77:1380-93.

35. Yang CD, Chen $Y H$, Huang HY, Huang HD, Tseng CP. CRP represses the CRISPR/Cas system in Escherichia coli: evidence that endogenous CRISPR spacers impede phage P1 replication. Mol Microbiol. 2014;92:1072-91.

36. Shinkai A et al. Transcription activation mediated by a cyclic AMP receptor protein from Thermus themophilus HB8. J Bacteriol. 2007:189:3891-901.

37. Brouns SJ, Jore MM, Lundgren M, Westra ER, Slijkhuis RJ, et al. Small CRISPR RNAs guide antiviral defense in prokaryotes. Science. 2008;321:960-4.

38. Pougach K, Semenova E, Bogdanova E, Datsenko KA, Djordjevic M, et al. Transcription, processing and function of CRISPR cassettes in Escherichia coli. Mol Microbiol. 2010;77:259-72

39. Almendros C, Guzmán NM, Díez-Villaseñor C, García-Martínez J, Mojica FJ. Target motifs affecting natural immunity by a constitutive CRISPR-Cas system in Escherichia coli. Plos ONE. 2012;7:e50797.

40. Vercoe RB, Chang JT, Dy RL, Taylor C, Gristwood T, et al. Cytotoxic chromosomal targeting by CRISPR/Cas systems can reshape bacterial genomes and expel or remodel pathogenicity islands. Plos Genet. 2013;9, e1003454.

41. Yosef I, Goren MG, Kiro R, Edgar R, Qimron U. High-temperature protein G is essential for activity of the Escherichia coli clustered regularly interspaced short palindromic repeats (CRISPR)/Cas system. Proc Natl Acad Sci U S A. 2011;108:20136-41.

42. Nonaka G, Blankschien M, Herman C, Gross CA, Rhodius VA. Regulon and promoter analysis of the $E$. coli heat-shock factor; sigma32, reveals a multifaceted cellular response to heat stress. Genes Dev. 2006;20:1776-89.

43. Wade JT, Castro Roa D, Grainger DC, Hurd D, Busby SJ, Struhl K, et al. Extensive functional overlap between sigma factors in Escherichia coli. Nat Struct Mol Biol. 2006;13:806-14

44. Ivančić-Baće I, Radovčić M, Bočkor L, Howard JL, Bolt EL. Cas3 stimulates runaway replication of a ColE1 plasmid in Escherichia coli and antagonises Rnase HI. RNA Biol. 2013;10:770-8.

45. Miller JH. Experiments in Molecular Genetics. Cold Spring Harbor: NY: Cold Spring Harbor Laboratory Press; 1992.

46. Sonden B, Uhlin BE. Coordinated and differential expression of histone-like proteins in Escherichia coli: regulation and function of the H-NS analog StpA. EMBO J. 1996;15:4970-80.

47. Datsenko KA, Wanner BL. One-step inactivation of chromosomal genes in Escherichia coli K-12 using PCR products. Proc Natl Acad Sci U S A. 2000;97:6640-5.

\section{Submit your next manuscript to BioMed Central and we will help you at every step:}

- We accept pre-submission inquiries

- Our selector tool helps you to find the most relevant journal

- We provide round the clock customer support

- Convenient online submission

- Thorough peer review

- Inclusion in PubMed and all major indexing services

- Maximum visibility for your research

Submit your manuscript at www.biomedcentral.com/submit
C Biomed Central 